\title{
Molecular Imprinting Electrochemical Sensor for Sensitive Creatinine Determination
}

\author{
Zhenyu Zhang ${ }^{1}$, Yang Li $^{2}$, Xiaoqin Liu ${ }^{1}$, Yanhui Zhang ${ }^{2}$ and Dongmei Wang, \\ ${ }^{1}$ Department of Nephrology, Hongqi Hospital Affiliated to Mudanjiang Medical University, \\ Mudanjiang, Heilongjiang, 157000, P.R. China \\ ${ }^{2}$ Department of Orthopedic Surgery, Hongqi Hospital Affiliated to Mudanjiang Medical University, \\ Mudanjiang, Heilongiiang, 157000, P.R. China \\ ${ }^{3}$ Department of Laboratory Medicine, Hongqi Hospital Affiliated to Mudanjiang Medical University, \\ Mudanjiang, Heilongjiang, 157000, P.R. China \\ *E-mail: dongmeiwang3@163.com
}

doi: $10.20964 / 2018.03 .67$

Received: 1 November 2017 / Accepted: 14 January 2018 / Published: 5 February 2018

Creatinine has been considered indicative of rental condition measurement after a dialysis. In the present work, a silver nanoparticles (AgNPs)/polyoxometalate functionalized reduced graphene oxide (rGO) coated glassy carbon electrode (GCE) based molecular imprinted voltammetric biosensor was for the first time prepared for the analysis of creatinine. XRD and X-ray photoelectron spectroscopy (XPS) measurements were used for the characterization of the modified surface. The limit of detection (LOD) was obtained as $1.51 \times 10^{-11} \mathrm{M}$, with a linear range of 0.05-1.5 nM. And the developed biosensor has been used for the detection of real specimens with desirable stability, recovery and selectivity.

Keywords: Molecular imprinting; Electrochemical sensor; Creatinine; Rental disease; Saliva

\section{FULL TEXT}

(C) 2018 The Authors. Published by ESG (www.electrochemsci.org). This article is an open access article distributed under the terms and conditions of the Creative Commons Attribution license (http://creativecommons.org/licenses/by/4.0/). 